\title{
THE ACCUMULATION OF ELECTROLYTES
}

\author{
V. Models Showing Accumulation and a Steady State \\ By W. J. V. OSTERHOUT AND W. M. STANLEY \\ (From the Laboratories of The Rockefeller Institute for Medical Research) \\ (Accepted for publication, April 9, 1932)
}

Previous papers ${ }^{1}$ point out the importance of the problem of accumulation in Valonia, and demonstrate that accumulation does not depend on the Donnan equilibrium or on the presence of ions or molecules inside which cannot pass out through the protoplasm. The experiments suggest that the following factors are important:

1. Permeability is determined by the properties of a continuous non-aqueous phase at both the inner and outer surface of the protoplasm.

2. Potassium and sodium penetrate chiefly as $\mathrm{KOH}$ and $\mathrm{NaOH}$ which may react with organic acids in the protoplasm to form salts which are decomposed by carbonic and other organic acids on reaching the sap.

3. The osmotic pressure of the sap is thereby raised and water enters.

4. This process tends toward a steady state where water and electrolyte enter at about the same rate, thus keeping the composition of the sap approximately constant as the cell grows.

5. Potassium penetrates more rapidly than sodium and in consequence potassium predominates over sodium in the sap.

6. Potassium accumulates inside because the sap is more acid than the external solution.

In order to see how far these suggestions form a workable scheme, it seemed desirable to test them by making a model. ${ }^{2}$

${ }^{1}$ Osterhout, W. J. V., (a) Proc. Soc. Exp. Biol. and Med., 1926-27, 24, 234. (b) J.Gen. Physiol., 1930-31, 14, 285. (c) Biol. Rev., 1931, 6, 369. (d) Jacques, A. G., and Osterhout, W. J. V., J. Gen. Physiol., 1930-31, 14, 301.

${ }^{2}$ The first models of this sort were made by the senior author 3 years ago. Reference was made to such models in a recent publication $(c f .1 c)$. See also Osterhout, W. J. V., and Stanley, W. M., Proc. Soc. Exp. Biol. and Med., 1931-32, 29,577 . 
We suppose that to enter Valonia electrolytes must traverse the outer non-aqueous layer of the protoplasm, ${ }^{3}$ then an aqueous layer, and finally an inner non-aqueous layer. As all the essential principles can be illustrated by one non-aqueous phase as well as by two, we use a model with a single non-aqueous layer ( $B$, Fig. 1) placed between two aqueous phases, one of which, $C$, represents the sap; the other, $A$, corresponds to the solution bathing the outside of the living cell.

This model is a modification of the one employed by Irwin. ${ }^{4}$

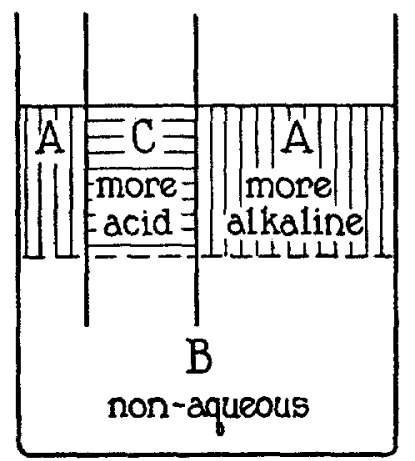

FIG. 1. Diagram of a model consisting of a non-aqueous layer, $B$, separating an aqueous layer, $C$ (representing the cell sap), from an alkaline aqueous layer, $A$ (representing the external solution).

A typical "large" model which will be called Model I was constituted as follows: About $900 \mathrm{cc}$. of the non-aqueous liquid was placed in the bottom of a battery jar $(B$, Fig. 2) $15 \mathrm{~cm}$. in diameter and $22 \mathrm{~cm}$. tall. Over this was placed about 2600 cc. of the alkaline solution so that the non-aqueous liquid formed a layer $(B)$ about $5 \mathrm{~cm}$. deep on the bottom of the jar, over which the aqueous alkaline solution formed a layer $(A)$ about $15 \mathrm{~cm}$. deep. A bell-shaped apparatus $(D)$ was then lowered into the battery jar until its bottom edge was about $3 \mathrm{~cm}$. below the surface of the non-aqueous liquid. This apparatus was prepared by sealing a piece of glass tubing, about $20 \mathrm{~cm}$. long and having an internal diameter of $1.7 \mathrm{~cm}$., to the bottom half of a $400 \mathrm{cc}$. beaker which had a hole of suitable size in the center of

${ }^{3}$ Osterhout, W. J. V., Biol. Rev., 1931, 6, 369.

4 Irwin, M., Proc. Soc. Exp. Biol. and Med., 1928-29, 26, 125; J. Gen. Physiol., $1928-29,12,407$. 
the bottom. This gave an apparatus about $25 \mathrm{~cm}$. high, the lower portion of which consisted of a bell $4.5 \mathrm{~cm}$. high and $8.5 \mathrm{~cm}$. in diameter, which allowed the liquid in $B$ and the liquid in $C$ to have a fairly large surface of contact and yet permitted $C$ to be of comparatively small volume. The alkaline liquid trapped in the bell when it was lowered was removed, and the interior of the bell flushed out with $100 \mathrm{cc}$. of distilled water by means of a pipette. Then the required solution was slowly added to the inside of the bell.

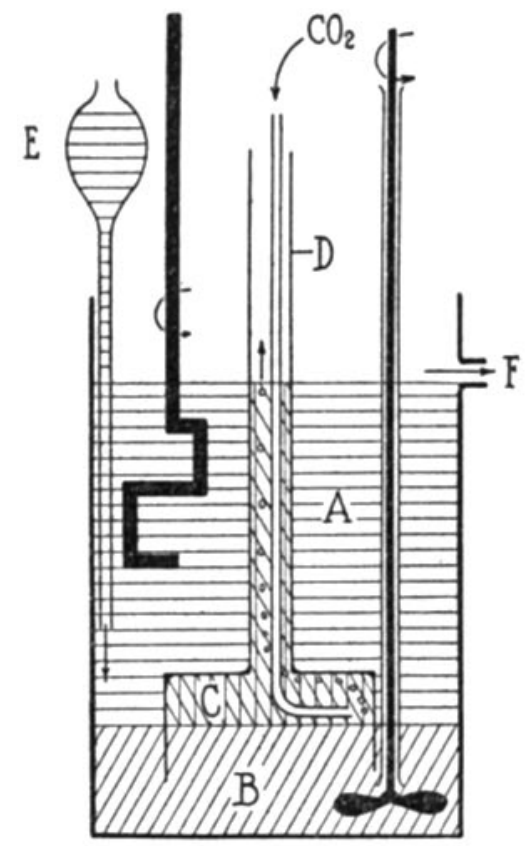

FIG. 2. Details of a model with a non-aqueous layer, $B$, separating two aqueous layers, $A$ and $C$ : all the layers are stirred.

When $\mathrm{CO}_{2}$ was used as the source of the acid for $C$ the bubbling stream of $\mathrm{CO}_{2}$ from a tank was used as the stirrer for $C$ : otherwise a glass stirrer was employed in $C$. The liquid in $A$ was stirred by means of a bent glass rod. Layer $B$ was stirred by means of a propeller placed so that the liquid was continually moved towards $C$. The shaft of the glass propeller for $B$ was enclosed in a glass tube so that the interface between $B$ and $A$ was not disturbed.

In experiments where the alkaline solution $A$ was continually renewed, the new solution was supplied from a separatory funnel $E$ usually at the rate of 2 liters per day and the used solution was allowed to flow out the overflow outlet at $F$. After the steady state was reached the volume of $C$ was maintained approximately con- 
stant by the periodic removal of small amounts of liquid by means of a pipette. This was necessary because at the steady state the volume of $C$ increases regularly. Thus the periodic removal of samples of $C$ for analysis in no way depleted the volume of $C$ in the model. The actual volume of $C$ does not appear to affect the steady state, but it does affect the time required to reach the steady state, since the smaller the volume of liquid $C$, the more quickly is $C$ affected by changes in $A$.

A smaller model, which will be called Model II, was prepared by using an ordinary $400 \mathrm{cc}$. Pyrex beaker to which an overflow outlet had been attached, as the outer container. The inner container consisted of a piece of large glass tubing 10 $\mathrm{cm}$. long and $4 \mathrm{~cm}$. in diameter, with its lower end $2 \mathrm{~cm}$. below the top of the liquid in $B$, which formed a layer $5 \mathrm{~cm}$. deep. The volume of solution in $C$ was usually $20 \mathrm{cc}$. although this may be varied widely $(10$ to $45 \mathrm{cc}$.) by changing the height of the guaiacol-p-cresol layer, which also automatically regulates the volume of the solution in $A$.

A third model, which will be designated as Model III, is somewhat similar to Model I but the stirring is better and the surfaces between $A$ and $B$ and between $B$ and $C$ are much larger. The volume of the non-aqueous mixture has been greatly enlarged and the volume of $C$ has been diminished. Hence potassium moves across about 25 times as rapidly as in Model I.

The temperature varied between $20^{\circ}$ and $25^{\circ} \mathrm{C}$.

Potassium was determined by the centrifuge method of Arrhenius, ${ }^{5}$ as used by Sherrill. ${ }^{6}$ This method was selected because of its great rapidity, as it was possible to make a fairly accurate potassium determination in less than 5 minutes. It is believed that this method is sufficiently accurate for comparative values, as in obtaining a time curve for increase of potassium concentration as in the experiments just described. The amount of unknown solution was adjusted so that the height of the precipitate in the centrifuge tube (Fig. 3) was always within about 20 per cent of that in the standard centrifuge tube with which it was compared. The standard used was $5 \mathrm{cc}$. of $0.5 \mathrm{M}$ potassium which gave a precipitate upon centrifuging at about 1500 revolutions per minute for 3 minutes, varying very little from $2.6 \mathrm{~cm}$. in height in the centrifuge tube. The concentration of potassium when the model had reached a steady state was usually checked by the perchlorate method. The potassium determinations made by the centrifuge method were accurate to within 5 per cent.

Sodium was determined by a centrifuge method which made use of the precipitate obtained with the magnesium uranyl acetate solution of Caley and Foulk. ${ }^{7}$ This precipitate was centrifuged in the tubes used for potassium and the height of the column was in each case compared with that given by a known amount of sodium. The amount of unknown solution was adjusted so that the height of the

${ }^{5}$ Arrhenius, S., Med. k. Ventenskapskad. Nobelinst., 1920, 4, No. 6, 1.

${ }^{6}$ Sherrill, E., Ind. and Eng. Chem., 1921, 13, 227.

${ }^{7}$ Caley, E. R., and Foulk, C. W., J. Am. Chem. Soc., 1929, 51, 1664. 
precipitate in the centrifuge tube was always within about 20 per cent of that of the standard centrifuge tube with which it was compared. The standard used for sodium was $1 \mathrm{cc}$. of $0.0319 \mathrm{M}$ sodium which gave a precipitate varying very little from $2.7 \mathrm{~cm}$. in height. For example, if the unknown solution were known to contain somewhere near $0.05 \mathrm{~m}$ sodium, either by estimate based upon previous knowledge of the solution, or by means of a rough preliminary determination, then exactly $0.5 \mathrm{cc}$. of the unknown solution was placed in a centrifuge tube, made slightly acid to phenolphthalein with acetic acid (if already acid from mineral acids, these are neutralized with $\mathrm{KOH}$ and then made acid with acetic acid), and $10 \mathrm{cc}$. of the magnesium uranyl acetate added. The mixture was stirred for 30 minutes and then centrifuged at about 1500 revolutions per minute for 3 minutes. The concentration of sodium was then calculated from the height of this precipitate as compared with the standard. The sodium values so obtained were within 7 per cent of the sodium values obtained by the difference of the weights of the total chlorides or sulfates and the weight of $\mathrm{KCl}$ or $\mathrm{K}_{2} \mathrm{SO}_{4}$, corresponding to the weight of potassium perchlorate found.

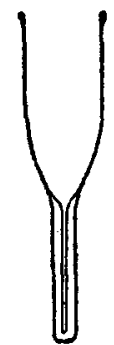

Fig. 3. Centrifuge tube for rapid determination of sodium and potassium consisting of a tube 3 to $6 \mathrm{~cm}$. long with an internal diameter of about $1 \mathrm{~mm}$. closed at one end and sealed to a piece of glass tubing 4 to $5 \mathrm{~cm}$. long and about $2.4 \mathrm{~cm}$. in diameter at the tip.

The determination of sodium bicarbonate in $A$ was made by precipitation with $\mathrm{Ba}$ which was then converted to $\mathrm{BaSO}_{4}$, and weighed as such.

Chlorides were determined by the Volhard method; sulfates as $\mathrm{BaSO}_{4}$.

The authors desire to thank Dr. Marian Irwin for determining the $\mathrm{pH}$ values colorimetrically (using her modifications of the standard methods). These measurements were repeated by the authors using the same methods and the results were confirmed. To avoid loss of $\mathrm{CO}_{2}$ from the liquid in $C$ samples withdrawn in a pipette were delivered at the bottom of a test-tube beneath a layer of paraffin oil. The upper portion of the liquid in the pipette was rejected.

By using a comparator block $^{8}$ for the liquid in $A$ (colored by guaiacol) it was

${ }^{8}$ The solution containing guaiacol was always placed toward the source of light in the comparator block. Comparison was made with the block in this position and the block was then reversed. The guaiacol solution, when turbid, can often be cleared by warming. 
possible, with sufficient practice, to read differences of $0.1 \mathrm{pH}$ in the region of 9.4, employing cresol phthalein ${ }^{9}$ as indicator. To ascertain whether guaiacol or $p$-cresol ${ }^{10}$ could affect the indicator (aside from an effect on the $\mathrm{pH}$ value) the following experiments were made. Since the solution used in $A$ usually contained $0.04 \mathrm{M}$ potassium (in the form of guaiacolate and of cresolate) $+0.01 \mathrm{M}$ $\mathrm{KHCO}_{3}$ a solution of double this concentration was made up and allowed to stand until the usual purplish color developed. It was found by the use of cresol phthalein to have a $\mathrm{pH}$ value of 9.3 : we may call this $X_{1}$. Buffer ${ }^{11}$ of this $\mathrm{pH}$ value and of the same ionic strength (made so by the addition of $\mathrm{KCl}$ ) was prepared: we may call this $X_{2}$. Equal volumes of $X_{1}$ and $X_{2}$ were mixed to form $X_{3}$. Presumably this involved little or no change in $\mathrm{pH}$ value. A colorimetric determination of $X_{3}$ (made immediately after adding thymol blue or cresol phthalein) gave a slightly higher $\mathrm{pH}$ value than for the pure buffer, $X_{2}$ (less than $0.1 \mathrm{pH}$ higher in the case of borate buffer and less than $0.2 \mathrm{pH}$ higher in the case of glycocoll buffer). Hence we may conclude that any disturbance, due to the action of guaiacol or $p$-cresol on the indicator may be neglected in the present case where only approximate values are needed. A repetition using one-half the concentration and employing cresol phthalein (the $\mathrm{pH}$ value being about 9.7) gave a similar result.

For the liquid in $C$ similar experiments were made by using pure buffer and buffer saturated with guaiacol. Differences of $0.1 \mathrm{pH}$ could easily be read by using cresol red. Here the concentration of guaiacol was much lower.

The buffers had in all cases about the same ionic strength as the samples and were carefully checked by means of the hydrogen electrode. ${ }^{12}$ The indicators (freshly made up) were sufficiently close to isohydric to avoid disturbing effects. Care was taken to make prompt readings before any change in color occurred.

There is a little variation in the $\mathrm{pH}$ value of $A$ in the steady state, due to slight variations in the rate of flow of the external solution and variations in the rate at which $\mathrm{CO}_{2}$ or bicarbonate diffuses in from $C$ (the amount picked up from the air is negligible).

\footnotetext{
${ }^{\theta}$ Especial care was devoted to selecting test-tubes of uniform size and to their cleanliness. Light from a daylight lamp was reflected from a metal surface painted with white lead and was brought to the optimum intensity. The comparator block was screened on all sides so that no extraneous glare disturbed the operator. The amount of indicator was reduced as far as was compatible with good reading.

${ }^{10} \mathrm{~A}$ saturated solution of $p$-cresol in water at $20^{\circ} \mathrm{C}$. is about $0.2 \mathrm{M}$ and that of guaiacol about $0.14 \mathrm{M}$.

${ }^{11}$ Both borate and glycocoll buffers were used. Regarding borate buffers see: Michaelis, L., J. Biol. Chem., 1930, 87, 33.

${ }^{12}$ In the case of the hydrogen and glass electrodes there is some uncertainty as to the need for correction of liquid junction potentials at higher ionic strengths and at high and low $\mathrm{pH}$ values ( $c f$. MacInnes, D. A., and Belcher, D., J. Am. Chem. Soc., 1931, 53, 3315; also Clark, W. M., The determination of hydrogen ions, The Williams \& Wilkins Co., Baltimore, 3rd edition, 1928).
} 
In a preliminary experiment with Model I, using $2000 \mathrm{cc}$. of $0.03 \mathrm{M}$ $\mathrm{KOH}$ in $A$ and $100 \mathrm{cc}$. of $1.0 \mathrm{M} \mathrm{HCl}$ in $C$, there was an accumulation of $\mathrm{KCl}$ in $C$ amounting in the course of 115 hours to $0.43 \mathrm{M}$. The concentration in $A$ fell off so that the ratio of potassium in $A$ and $C$ was $0.43 \div 0.0019=226$ or an accumulation of potassium in $C$ of over 200 times that in $A$.

At the end of 67 hours $A$ was found to be neutral (due to the outward passage of $\mathrm{HCl}$ ) and to contain $0.008 \mathrm{M}$ potassium and $0.007 \mathrm{M}$ chloride, so $A$ was removed and replaced by a $0.008 \mathrm{M} \mathrm{KOH}$ solution (at this time there was $0.008 \mathrm{M}$ potassium outside and $0.36 \mathrm{M}$ potassium inside so that there was a marked accumulation). This was found to be necessary again at the end of 98 hours when $A$ was removed and replaced by a $0.0035 \mathrm{MOH}$ solution. At the end of 115 hours the concentration of potassium in $A$ had fallen from $0.03 \mathrm{M}$ to $0.0019 \mathrm{M}$ due to the passage of 56.9 millimols of potassium from $A$ into $C$. During this same period of time 21 millimols of $\mathrm{HCl}$ passed from $C$ into $A . \quad B$ consisted of 70 per cent guaiacol +30 per cent $p$-cresol.

Most of the experiments were made by using $\mathrm{CO}_{2}$ as the acid inside. As an example of the results we may consider an experiment in which the non-aqueous layer $(B)$ consisted of 70 per cent guaiacol and 30 per cent $p$-cresol; at the start the aqueous solution in $A$ contained $0.05 \mathrm{M} \mathrm{KOH}$ and $C$ consisted of distilled water; $\mathrm{CO}_{2}$ was continually bubbled through $C$ during the entire experiment.

At the end of 50 hours the concentration of potassium in $C$ was more than 5 times as great as in $A$ so that it was evident that a marked accumulation was possible. ${ }^{13}$ Practically all of this was in the form of $\mathrm{KHCO}_{3}$. A certain amount of guaiacol and $p$-cresol dissolved ${ }^{10}$ in $C$ and much of the $\mathrm{KOH}$ in $A$ was converted to salts of guaiacol and p-cresol.

It seemed desirable to keep the solution in $A$ approximately constant. This could be done by allowing $\mathrm{KOH}$ to flow in a steady stream through $A$. But as this would remove some of the non-aqueous liquid in $B$ it was decided to shake the $\mathrm{KOH}$ with the mixture of guaiacol and $p$-cresol before allowing it to enter $A$. This, of course, converts most of the $\mathrm{KOH}$ to $\mathrm{K}$-guaiacolate and $\mathrm{K}$ - $p$-cresolate but

${ }^{13}$ Accumulation also occurred when formic or citric acid was placed in $C$. Both of these acids passed through $B$ to $A$ very freely, consequently it was necessary to add formic and citric acid to $C$ daily. 
the principle remains unchanged since in any case these salts must be formed and it makes no difference whether they are formed before or after entering $A$ : hence we may continue to speak of the penetration of $\mathrm{KOH}$ into $B$ and $C$ even though it be shaken with the liquid taken from $B$ before entering $A$.

A new experiment was started in which $0.05 \mathrm{M} \mathrm{KOH}$ was shaken

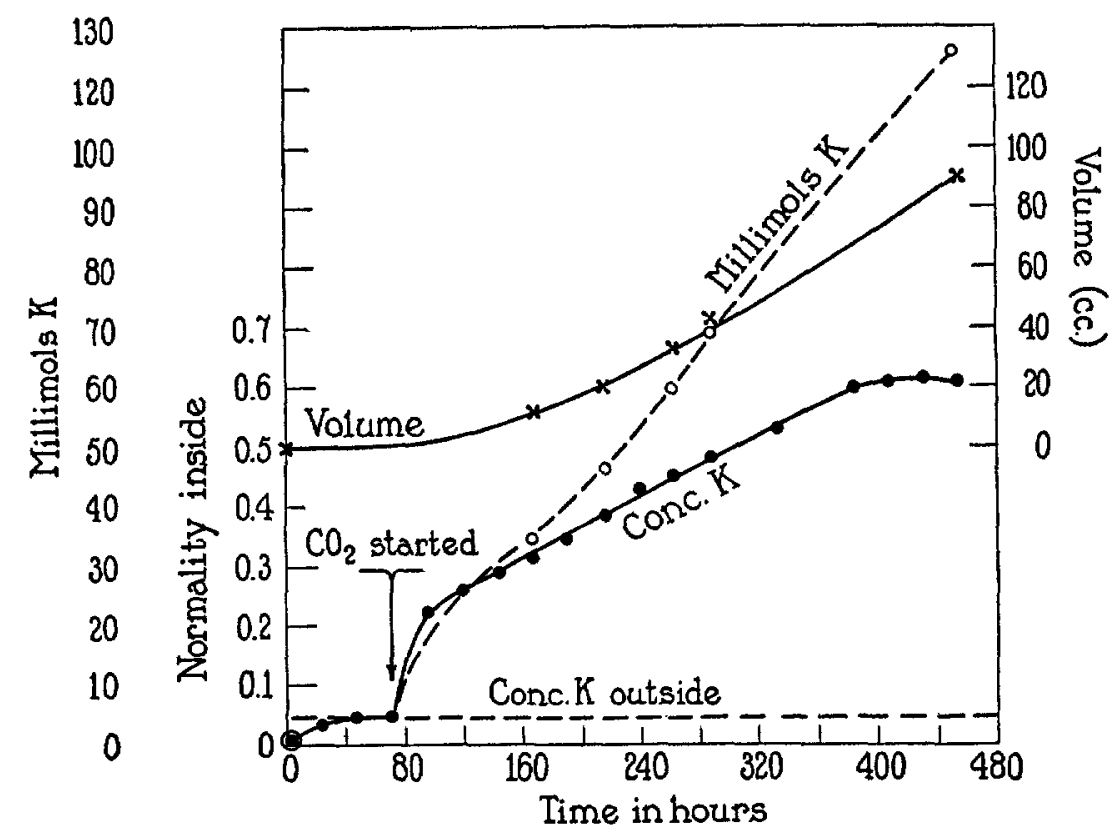

FIG. 4. Changes in the "artificial sap" in an experiment (No. 65, Table I) with $0.05 \mathrm{M} \mathrm{KOH}$ (previously shaken with some of the non-aqueous mixture of 70 per cent guaiacol and 30 per cent $p$-cresol taken from $B$ ) in $A$ and distilled water in $C$. There was no accumulation until the $\mathrm{CO}_{2}$ began to bubble in $C$.

with a guaiacol- $p$-cresol mixture ${ }^{14}$ for 2 minutes, allowed to separate, and then made to flow in a steady stream through $A .{ }^{15}$ Under these

14 The amount of this was so small that it took up only a negligible amount of potassium.

${ }^{15}$ This is essentially the same as placing $0.05 \mathrm{M} \mathrm{KOH}$ in $A$ and allowing the organic salts to form at the surface of $B$ and then pass into $B$. As fast as potassium disappears from $A$ it may be replaced by the addition of fresh KOH (or a steady stream of KOH may be allowed to flow through $A$ : but this carries off more of the non-aqueous mixture). 
circumstances the flowing liquid in $A$ (containing about $0.05 \mathrm{M}$ potassium combined with guaiacol and $p$-cresol) presumably dissolved little or none of the guaiacol or $p$-cresol in $B$ but salts of potassium and sodium passed into $B$ and on reaching $C$ (where $\mathrm{CO}_{2}$ was bubbling) were decomposed to form bicarbonates ${ }^{16}$ and carbonates.

During the first 71 hours no $\mathrm{CO}_{2}$ was bubbled through $C$, and potassium entered until its concentration was equal to that in the external solution $(0.05 \mathrm{M})$. There was no increase in the volume of liquid in $C$ (Fig. 4).

The bubbling of $\mathrm{CO}_{2}$ was then commenced and in the course of 312 hours the concentration ${ }^{17}$ of potassium in $C$ rose to 0.61 or 12 times that in the external solution (Exp. 65, Table I). From this time on water was taken up as rapidly as electrolyte ${ }^{18}$ so that although potassium continued to enter (as shown by the curve labelled "Millimols $\mathrm{K}$," Fig. 4) the concentration in $C$ remained approximately constant. This is presumably analogous to what happens when Valonia takes up water and grows while the concentrations in the sap remain approximately constant.

This was repeated with Model II which had larger specific surfaces so that the speed of penetration was greatly increased. The ratios of the volumes, however, remained as before ${ }^{19}$ and the steady state was reached with $0.60 \mathrm{~m}$ potassium inside (Exp. 73, Table I). With Model III somewhat higher values were attained (Table I).

Once established, the steady state is quite stable, responding but slowly to changes in concentration in $A$ or to changes in the rate of bubbling $\mathrm{CO}_{2}$ in $C$. In this respect it may resemble certain living cells.

A rather extreme test of the stability of the steady state is shown in

${ }^{16}$ With no $\mathrm{CO}_{2}$ bubbling through $C$ the entrance of potassium was very slow and no accumulation occurred. This is to be expected since as soon as the concentration of potassium in $C$ became equal to that in $A$ the $\mathrm{pH}$ values would be approximately equal.

17 This was mostly $\mathrm{KHCO}_{3}$.

18 This evidently depends on the fact that the osmotic pressure inside increases as the concentration of $\mathrm{KHCO}_{3}$ and $\mathrm{NaHCO}_{3}$ increases.

${ }_{19}$ The external solution in all these cases contained $0.05 \mathrm{M}$ potassium in the form of guaiacolate except for $0.008 \mathrm{M}$ to $0.012 \mathrm{M} \mathrm{KHCO}_{3}$ (due to $\mathrm{CO}_{2}$ diffusing from $C$ through $B$ into $A$ and varying with the rate of flow of the liquid from $E$, Fig. 2). 
TABLE I

Steady State

(When B Consists of 70 Per Cent Guaiacol +30 Per Cent p-Cresol)

\begin{tabular}{|c|c|c|c|c|c|c|c|c|c|}
\hline \multirow{2}{*}{ Model } & \multirow{2}{*}{$\begin{array}{c}\text { Ex- } \\
\text { peri- } \\
\text { ment }\end{array}$} & \multicolumn{2}{|l|}{ Outside $(A)$} & \multicolumn{2}{|l|}{ Inside $(C)$} & \multicolumn{2}{|c|}{$\begin{array}{c}\text { Activity } \\
\text { coefficient } \\
\text { of } K\end{array}$} & \multirow{2}{*}{$\begin{array}{l}\frac{\Delta \mathrm{F}}{2.3 R T} \\
\mathrm{for} \\
\mathrm{KOH}\end{array}$} & \multirow{2}{*}{$\begin{array}{l}\text { Hrs. } \\
\text { required } \\
\text { to reach } \\
\text { steady } \\
\text { state }\end{array}$} \\
\hline & & Composition & $\mathrm{pH}$ & Composition & $\mathrm{pH}$ & $\begin{array}{l}\text { Out- } \\
\text { side }\end{array}$ & Inside & & \\
\hline II & 74 & $\begin{array}{ll}0.04 & \text { K-org.* } \\
0.01 & \text { KHCO }_{3} \dagger\end{array}$ & 9.1 & $0.63 \mathrm{KHCO}_{3}$ & 7.5 & 0.817 & 0.63 & 0.61 & - \\
\hline III & 68 & $\begin{array}{l}0.033 \mathrm{~K} \text {-org. } \\
0.017 \mathrm{KHCO}_{3}\end{array}$ & 9.1 & $0.75 \mathrm{KHCO}_{3}$ & 7.5 & 0.817 & 0.618 & 0.55 & 18 \\
\hline III & 69 & $\begin{array}{l}0.033 \mathrm{~K} \text {-org. } \\
0.017 \mathrm{KHCO}_{3}\end{array}$ & 9.1 & $0.83 \mathrm{KHCO}_{3}$ & 7.5 & 0.817 & 0.612 & 0.51 & 18 \\
\hline I & 65 & $\begin{array}{ll}0.04 & \mathrm{~K} \text {-org. } \\
0.01 & \mathrm{KHCO}_{3}\end{array}$ & & $0.61 \mathrm{KHCO}_{3}$ & & & & & 312 \\
\hline II & 73 & $\begin{array}{ll}0.04 & \text { K-org. } \\
0.01 & \mathrm{KHCO}_{\mathrm{z}}\end{array}$ & & $0.60 \mathrm{KHCO}_{3}$ & & & & & 25 \\
\hline I & 66 & $\begin{array}{l}0.043 \mathrm{~K} \text {-org. } \\
0.007 \mathrm{KHCO}_{3} \\
0.043 \mathrm{Na}^{- \text {org. }} \\
0.007 \mathrm{NaHCO}_{3}\end{array}$ & 9.4 & $\begin{array}{l}0.73 \mathrm{KHCO}_{3} \\
0.45 \mathrm{NaHCO}_{3}\end{array}$ & 7.5 & 0.767 & 0.587 & 1.11 & 367 \\
\hline III & 78 & $\begin{array}{l}0.011 \mathrm{~K} \text {-org. } \\
0.014 \mathrm{KHCO}_{3}\end{array}$ & 8.9 & $0.34 \mathrm{KHCO}_{3}$ & 7.3 & 0.848 & 0.670 & 0.57 & 60 \\
\hline III & 79 & $\begin{array}{l}0.011 \mathrm{~K} \text {-org. } \\
0.014 \mathrm{KHCO}_{3}\end{array}$ & 8.8 & $0.32 \mathrm{KHCO}_{3}$ & 7.2 & 0.848 & 0.675 & 0.59 & 52 \\
\hline I & 64 & $\begin{array}{l}0.041 \mathrm{~K} \text {-org. } \\
0.009 \mathrm{KHCO}_{\mathrm{s}}\end{array}$ & 9.1 & $0.63 \mathrm{KHCO}_{3}$ & 7.6 & $0.817 \mid \mathrm{C}$ & 0.63 & 0.60 & 208 \\
\hline
\end{tabular}

* K-org. means potassium combined with guaiacol and p-cresol.

† The bicarbonate in $A$ was derived from $\mathrm{CO}_{2}$ or $\mathrm{HCO}_{3}$ - diffusing in from $C$.

Fig. 5. The steady state was reached ${ }^{20}$ at 208 hours with $0.63 \mathrm{M}$ $\mathrm{KHCO}_{3}$ inside (Exp. 64, Table I), and at 259 hours enough $\mathrm{KHCO}_{3}$

${ }^{20}$ In this experiment the external solution was $0.05 \mathrm{M} \mathrm{KOH}$ which had been shaken with liquid from $B$ (as in the previous experiment): $\mathrm{CO}_{2}$ was bubbled in $C$. 
was added to $C$ to make the concentration $1.1 \mathrm{M}$. After this potassium continued to enter as shown by the curve labelled "Millimols $K$ " but water entered so rapidly (as shown by the curve labelled "Volume") that the concentration of potassium approached its former

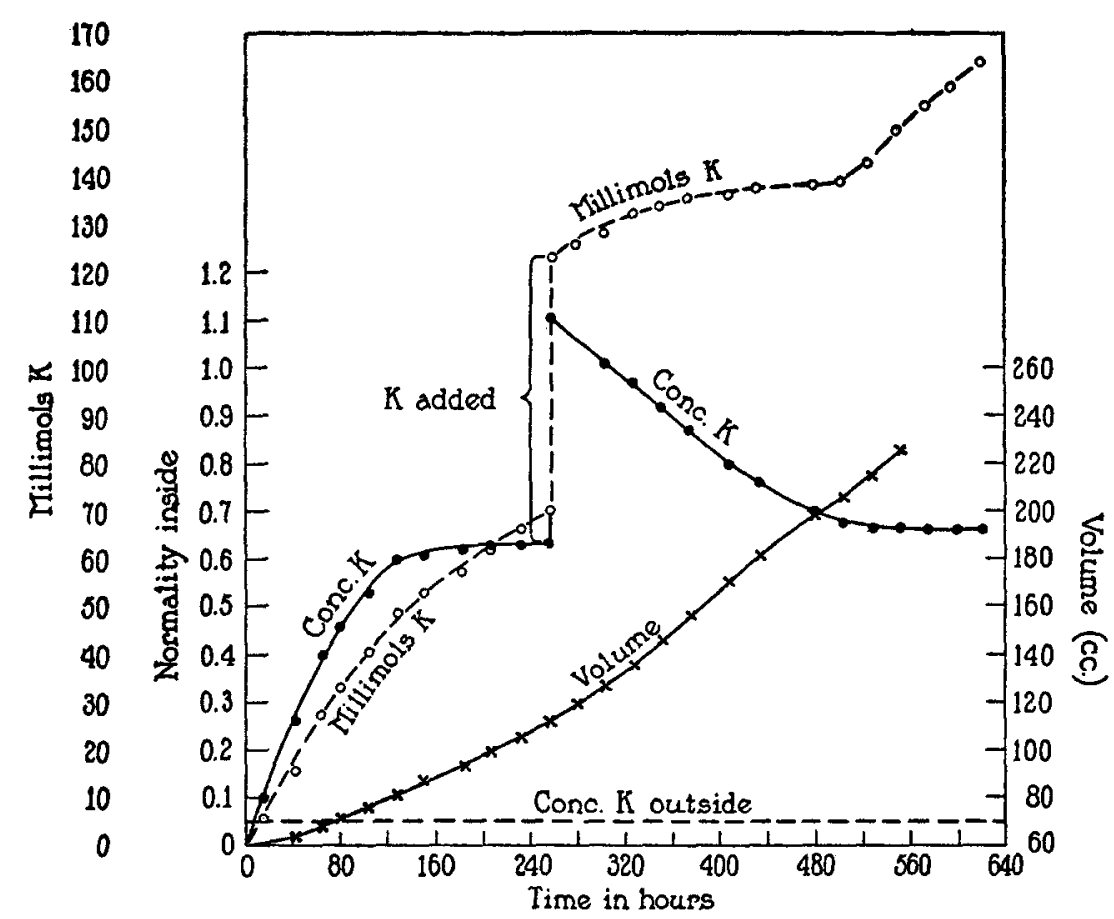

FIG. 5. Changes in the "artificial sap" in an experiment (No. 64, Table I) with $0.05 \mathrm{M} \mathrm{KOH}$ (previously shaken with some of the non-aqueous mixture of 70 per cent guaiacol and 30 per cent $p$-cresol taken from $B$ ) in $A$ and distilled water plus $\mathrm{CO}_{2}$ in $C$. After the steady state was reached enough $\mathrm{KHCO}_{3}$ was added to $C$ to raise the concentration of $\mathrm{KHCO}_{3}$ from $0.63 \mathrm{M}$ to $1.1 \mathrm{M}$. After this potassium continued to enter but as water passed in more rapidly (due to the increase in osmotic pressure in $C$ ) the concentration of potassium in $C$ fell off almost to the previous level of the steady state.

level. It is evident that the steady state can be approached from either side.

The steady state is attained more rapidly when the temperature is raised. The diffusion of all substances is accelerated but the 
transfer of water is hastened more than that of salt so that the steady state is reached at a lower salt concentration.

One of the most striking facts about Valonia is the selection of potassium in preference to sodium. To see whether the model would imitate this the experiment just described was repeated with $0.05 \mathrm{M}$ $\mathrm{KOH}+0.05 \mathrm{M} \mathrm{NaOH}$ in $A$ in place of $0.05 \mathrm{M} \mathrm{KOH}$. The results are

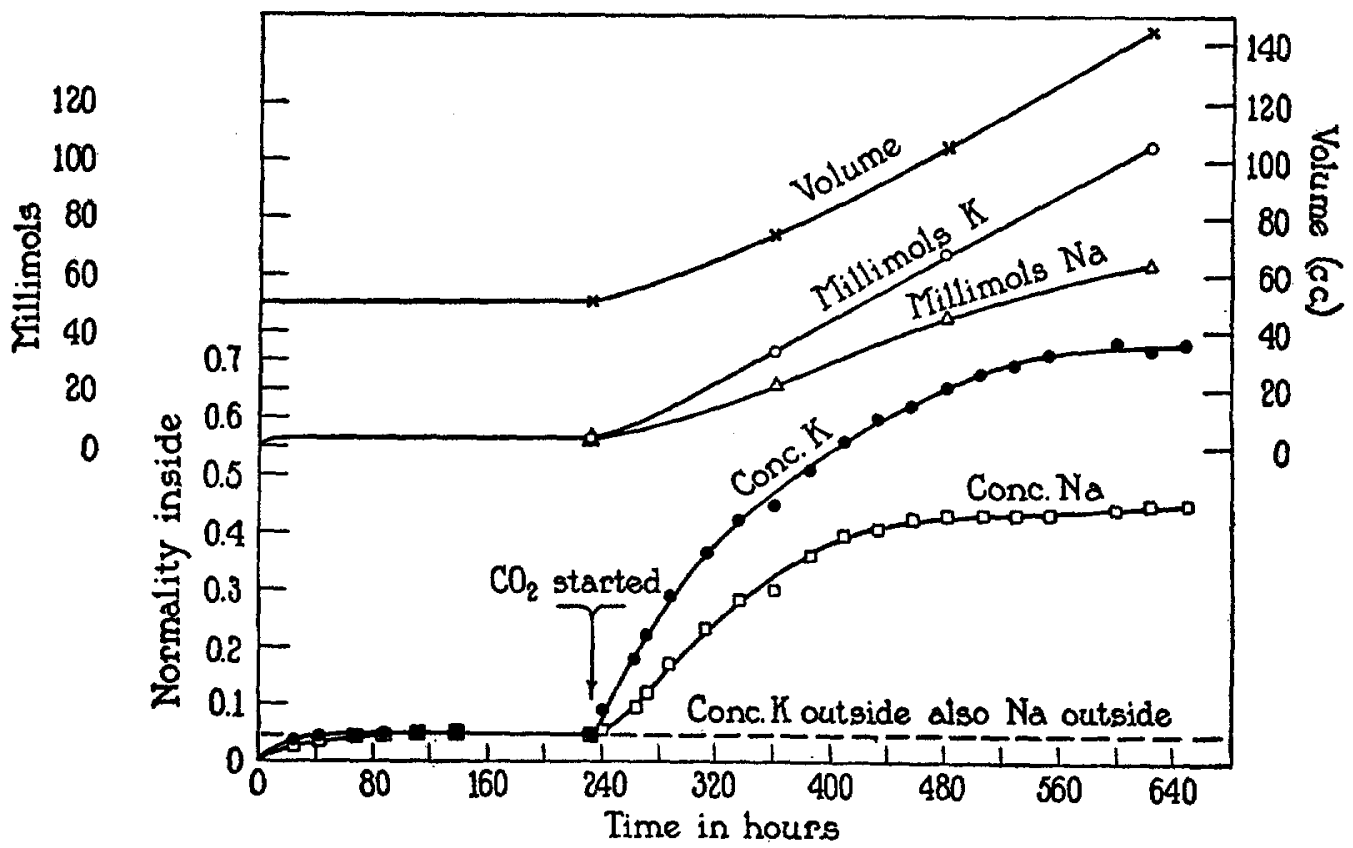

Frg. 6. Changes in the "artificial sap" in an experiment (No. 66, Table I) with $0.05 \mathrm{M} \mathrm{KOH}+0.05 \mathrm{M} \mathrm{NaOH}$ (previously shaken with some of the nonaqueous mixture of 70 per cent guaiacol +30 per cent $p$-cresol taken from $B$ ) in $A$ and distilled water plus $\mathrm{CO}_{2}$ in $C$. The ratio of potassium to sodium in the steady state is about 8 to 5 .

shown in Fig. 6. At the end of 367 hours after starting the $\mathrm{CO}_{2}$ the concentration of potassium was $0.71 \mathrm{M}$ (i.e. about 14 times that in $A$ ) and the concentration of sodium was $0.43 \mathrm{M}$ (i.e. about 8.6 times that in $A$ ). From this time on water entered about as rapidly as electrolyte, i.e. a steady state occurred which behaved like the steady states already discussed. (Exp. 66, Table I.) 
Variations of the non-aqueous mixture can change these relations. On increasing the proportion of $p$-cresol the $\mathrm{K} \div \mathrm{Na}$ ratio falls off. A preponderance of sodium over potassium is found with (a) $100 \mathrm{cc}$. cyclohexanol +2 gm. palmitic acid, (b) $50 \mathrm{cc}$. amyl alcohol $+4 \mathrm{gm}$. stearic or palmitic acid.

It would appear that in certain respects the model follows rather closely the hypothesis outlined in previous papers ${ }^{21}$ to explain the behavior of Valonia. Attention may be called to the following:

1. $\mathrm{KOH}$ tends to enter because the external product $\left(\mathrm{K}_{o}\right)\left(\mathrm{OH}_{o}\right)$ is greater $^{22}$ than the internal product $\left(\mathrm{K}_{i}\right)\left(\mathrm{OH}_{i}\right)$ (where the subscripts $o$ and $i$ denote activities outside and inside respectively).

2. Potassium predominates over sodium in $C^{2 s}$ (i.e., in the "artificial sap"), because the non-aqueous layer is more permeable to certain $\mathrm{K}$-compounds.

3. $\mathrm{KOH}$ combines with carriers in the non-aqueous phase to form organic salts which react with the weak organic acid in the "artificial sap."

4. The salts thus formed in the "artificial sap" raise its osmotic pressure above that of the external solution and in consequence water enters. In the model this occurs without restraint but in Valonia the cell wall can inhibit the entrance of water more or less completely. ${ }^{24}$

In Exp. 66 (Table I) the formation of bicarbonates of potassium and sodium raised the osmotic pressure in $C$ from nearly zero to more than 40 atmospheres (more than 10 times that of the external solution). If $\mathrm{CO}_{2}$ act thus in the living cell (as elsewhere suggested ${ }^{25}$ ) it plays an important rôle in the creation of osmotic energy in the cell.

5. Equilibrium is not attained but a steady state is reached in which the entrance of water keeps pace with that of electrolytes so that the

${ }^{21}$ Osterhout, W. J. V., J. Gen. Physiol., 1930-31, 14, 277; Biol. Rev., 1931, 6, 369.

${ }^{22}$ Unless the internal $\mathrm{pH}$ value be lower than the external there is no accumulation of potassium.

${ }^{23}$ The ratio $\mathrm{K} \div \mathrm{Na}$ is much greater in Valonia than in the model.

${ }^{24}$ The rate of increase in volume in $C$ with Model I was in the neighborhood of 10 per cent per day or more than 10 times that of Valonia under favorable laboratory conditions. The rate of stirring of the solutions and the extent of their surface are determining factors in the model.

${ }^{25}$ Osterhout, W. J. V., Proc. Soc. Exp. Biol. and Med., 1926-27, 24, 234; J. Gen. Physiol., 1930-31, 14, 285; Biol. Rev., 1931, 6, 369. 
composition of the sap remains approximately constant. This is presumably analogous to what is found in Valonia. In this steady state the difference between internal and external $\mathrm{pH}$ value is about 2 , both in the model and in Valonia.

In discussing the penetration of $\mathrm{KOH}$ into Valonia it has been stated elsewhere ${ }^{25}$ that this takes place as long as the external product $\left(\mathrm{K}_{\mathrm{o}}\right)$ $\left(\mathrm{OH}_{0}\right)$ is greater than the internal product $\left(\mathrm{K}_{i}\right)\left(\mathrm{OH}_{i}\right)$. In other words, it continues as long as there is a difference between the thermodynamic potential of $\mathrm{KOH}$ inside and outside. We may call this difference $\Delta F$ and write ${ }^{26}$

$$
\Delta F=2.3 R T \log \frac{\left(\mathrm{K}_{0}\right)\left(\mathrm{OH}_{o}\right)}{\left(\mathrm{K}_{i}\right)\left(\mathrm{OH}_{i}\right)}
$$

Since the ionic strength is nearly the same inside and outside we may substitute concentrations for activities and write

$$
\Delta F=2.3 R T \log \frac{(0.012) 10^{-6}}{(0.5) 10^{-8.2}}=2.3 R T(0.58)
$$

In the model $\mathrm{KOH}$ never reaches a condition of equilibrium in which $\left(\mathrm{K}_{o}\right)\left(\mathrm{OH}_{o}\right)=\left(\mathrm{K}_{i}\right)\left(\mathrm{OH}_{i}\right)$ but instead attains a steady state, where $\Delta F$ is not very different from what it is in Valonia. Since the ionic strength is not the same inside and outside we endeavor to approximate the activities. Probably the most reasonable way to do this, in the absence of actual determinations, is as follows: In one experiment (Table I, Exp. 74) the outside solution had in the steady state a $\mathrm{pH}$ value of 9.1 (i.e. $\mathrm{OH}_{o}=10^{-4.9}$ ) and contained $0.05 \mathrm{M}$ potassium (in the form of guaiacolate and bicarbonate ${ }^{27}$ ). For purposes of calculation we take the activity coefficient of potassium to be that of potassium in a solution of $\mathrm{KCl}$ of the same ionic strength, in which the activities of potassium and chloride are regarded as equal. ${ }^{28}$ The activity

\footnotetext{
${ }^{26}$ This results from the equations $F_{\text {outside }}=F_{0}+2.3 R T \log \left(\mathrm{K}_{0}\right)\left(\mathrm{OH}_{o}\right)$ and $F_{\text {inside }}=F_{o}+2.3 R T \log \left(\mathrm{K}_{i}\right)\left(\mathrm{OH}_{i}\right)$, where $F$ is the thermodynamic potential and $F_{o}$ is the value of $F$ for $1 \mathrm{~mol}$ of $\mathrm{KOH}$ in the standard state. $C f$. Lewis, G. N., and Randall, M., Thermodynamics, New York, McGraw-Hill Book Co., Inc., 1923.

${ }^{27} \mathrm{CO}_{2}$ diffuses from $C$ into $A$ as the solution flows through $A$.

${ }^{28}$ MacInnes, D. A., J. Am. Chem. Soc., 1919, 41, 1086. Cf. Güntelberg, E., and Schiödt, E., Z. phys. Chem., 1928, 135, 393.
} 
coefficients thus obtained are by no means exact but they will at least give us an approximation sufficient for our present calculation. We then have

$$
\begin{aligned}
\Delta F & =2.3 R T \log \frac{\left(\mathrm{K}_{o}\right)\left(\mathrm{OH}_{o}\right)}{\left(\mathrm{K}_{i}\right)\left(\mathrm{OH}_{i}\right)} \\
& =2.3 R T \log \frac{(0.05)(0.817) 10^{-4.9}}{(0.63)(0.63) 10^{-6.5}} \\
& =2.3 R T(0.61)
\end{aligned}
$$

From this we see that if the $\mathrm{pH}$ value of Valonia sap were 5.5 (giving $\mathrm{OH}_{i}=10^{-8.5}$ ) the value of $\Delta F$ would be the same as in the model. Such a low value frequently occurs. We have used 5.8 in the equation but this may be a little too high to represent the usual value. In some experiments the values of $\Delta F$ were greater than this but in others less than in Valonia (Table I).

6. The thermodynamic potential of the potassium salt inside becomes greater than outside so that $\left(\mathrm{K}_{i}\right)\left(\mathrm{HCO}_{3 i}\right)>\left(\mathrm{K}_{0}\right)\left(\mathrm{HCO}_{3 o}\right)$. In Valonia the potassium salt inside is $\mathrm{KCl}$ and we find $\left(\mathrm{K}_{i}\right)\left(\mathrm{Cl}_{i}\right)>$ $\left(\mathrm{K}_{o}\right)\left(\mathrm{Cl}_{o}\right)$.

7. The steady state in our models and in Valonia differs from the Donnan equilibrium as is evident from Table II which shows some typical cases. (In the Donnan equilibrium all the ratios in each horizontal row should be equal.)

8. Does accumulation depend on the presence of ions which are unable to pass through the non-aqueous layer? Evidently not, for all the ions in the system can penetrate freely (this expression is used regardless of whether they exist in $B$ as ions or as molecules). The rate of penetration of $\mathrm{K}^{+}$and $\mathrm{Na}^{+}$is evident from Table $\mathrm{I}: \mathrm{H}^{+}$or $\mathrm{OH}^{-}$also penetrates since $\mathrm{HCl}$ passes out quite freely (see page 673) and this is true in much greater degree of citric and formic acids; furthermore $C$ becomes more alkaline as the experiment proceeds (e.g. rising from a $\mathrm{pH}$ value of less than 6 to 7.5 in Exp. 74, Table I). It is also evident that $\mathrm{HCO}_{3}^{-}$or $\mathrm{CO}_{2}$ penetrates freely: in Model I approximately $80 \mathrm{cc}$. of $\mathrm{CO}_{2}$ per hour in the form of $\mathrm{CO}_{2}$ or $\mathrm{HCO}_{3}{ }^{-}$passed from 
$C$ into $A$ (i.e., a little less than $2 \mathrm{cc}$. per square centimeter of surface per hour). It may be that $\mathrm{HCO}_{3}{ }^{-}$as such cannot penetrate rapidly ${ }^{29}$ but it can unite with $\mathrm{H}^{+}$and pass out as $\mathrm{H}_{2} \mathrm{CO}_{3}$ or $\mathrm{CO}_{2}$. For con-

TABLE II

Approximate Ratios of Internal and External Activities in the Steady State

\begin{tabular}{|c|c|c|c|c|c|c|}
\hline & $\frac{\mathrm{H}_{i}^{+}}{\mathbf{H}_{o}^{+}}$ & $\frac{\mathbf{K}_{i}^{+*}}{\mathbf{K}_{o}^{+}}$ & $\frac{\mathrm{Na}_{i}^{+*}}{\mathrm{Na}_{o}^{+}}$ & $\frac{\mathrm{HCO}_{30}^{-\dagger}}{\mathrm{HCO}_{3 i}^{-}}$ & $\frac{\mathrm{Cl}_{o}^{-}}{\mathrm{Cl}_{i}^{-}}$ & $\frac{G_{o}^{-\ddagger}}{G_{i}^{-}}$ \\
\hline Valonia & 158.5 & 41.6 & 0.18 & 102.4 & 0.97 & 一 \\
\hline $\begin{array}{l}\text { Exp. } 74, \\
\text { Table I }\end{array}$ & 39.8 & 9.7 & - & 0.043 & - & 39.8 \\
\hline $\begin{array}{l}\text { Exp. } 66, \\
\text { Table I }\end{array}$ & 79.4 & 11.2 & 7.6 & 0.012 & - & 79.4 \\
\hline
\end{tabular}

* The activity coefficients for $\mathrm{K}^{+}$and $\mathrm{Na}^{+}$are from Harned, H. S., J. Am. Chem. Soc., 1922, 44, 252;1929, 61, 416, assuming them to be equivalent to those of $\mathrm{Cl}$ in each case.

† Osterhout, W. J. V., and Dorcas, M. J., J. Gen. Physiol., 1925-26, 9, 255. The activity coefficients of $\mathrm{HCO}_{3}-$ are from Güntelberg, E., and Schiödt, E., $Z$. phys. Chem., 1928, 135, 393.

$\ddagger$ The concentration of $G^{-}$(guaiacol ion) was calculated from the hydrolysis equation $G^{-}=\frac{1.17\left(10^{-10}\right)}{10^{-14}}(\mathrm{H} G)\left(\mathrm{OH}^{-}\right)$. The value of $\mathrm{H} G$ (undissociated guaiacol) was estimated by observing how much guaiacol was taken up when, for example, in Experiment 74, $0.63 \mathrm{M} \mathrm{KHCO}_{3}$ was shaken up with an excess of guaiacol. This gave $0.113 \mathrm{M}$ whence $G_{i}^{-}=0.00042$. Taking $G_{o}^{-}=\mathrm{K} G$, we have $G_{o}$ $=0.04$ and $G_{o}^{-} \div G_{i}^{-}=95$. If the activity of $\mathrm{HG}$ be the same in $A$ and in $C$ then $G_{o} \div G_{i}=\mathrm{OH}_{o} \div \mathrm{OH}_{i}=10^{-4.9} \div 10^{-6.5}=39.8$. The use of concentrations in place of activities and uncertainties in both may account for the difference.

venience in discussion we shall define an ion of this sort as a penetrating ion. We may say that all the ions in our experiments are penetrating ions (and this may be the case in Valonia since there is very little

${ }^{29}$ Since the dielectric constant of guaiacol, which makes up 70 per cent of the non-aqueous mixture, is approximately 12 and that of $p$-cresol 5.6 (cf. International critical tables, New York, McGraw-Hill Book Co., Inc., 1929, 6, 92) it would seem that there must be some dissociation of the $\mathrm{CO}_{2}$ in the non-aqueous mixture and hence some passage of $\mathrm{HCO}_{3}{ }^{-}$as such. 
organic matter in the $\operatorname{sap}^{30}$ and the chief reactant, $\mathrm{CO}_{2}$, passes out freely). ${ }^{31}$

The question now arises whether such ions are to be regarded as diffusible in the Donnan sense. The answer to this question depends on definitions: let us consider the following.

(a) If we say that from the Donnan standpoint an ion is diffusible if its concentration diminish in $A$ and increase in $C$ (or vice versa) diffusibility is to be judged solely by changes in $A$ and $C$. Hence in the steady state (when there is no change in the composition of either $A$ or $C$ ) all the ions (including those which are rapidly accumulating) might, on this basis, be regarded as indiffusible, although all of them are penetrating ions.

(b) If, however, we prefer to say that with a system not in equilibrium only those ions are diffusible in the Donnan sense whose concentrations in $A$ and $C$ change in such a way as to approach a Donnan equilibrium we must regard the ions in our experiment as indiffusible since the system does not move toward a Donnan equilibrium even when the $\mathrm{CO}_{2}$ stops bubbling.

This may be illustrated by an experiment with Model III in which, after the steady state had been reached, the bubbling of $\mathrm{CO}_{2}$ was stopped and the progress of the system towards equilibrium was observed. When the $\mathrm{CO}_{2}$ stopped bubbling, $C$ contained $0.98 \mathrm{M} \mathrm{KHCO}_{3}+0.35 \mathrm{M} \mathrm{NaHCO}_{3}$. The system was left to itself except that the stirring was continued (the outside flow was stopped). After 16 days $C$ contained $0.20 \mathrm{M}$ potassium $+0.22 \mathrm{M}$ sodium (these were partly organic salts and partly bicarbonate) and the bicarbonate had fallen from $1.33 \mathrm{M}$ to $0.28 \mathrm{M}$.

During the same period the concentration in $A$ increased from $0.05 \mathrm{M}$ to $0.06 \mathrm{M}$ in the case of potassium, from 0.05 to $0.056 \mathrm{M}$ in the case of sodium, and from 0.021 to $0.047 \mathrm{M}$ in the case of bicarbonate. A control experiment showed that practically no $\mathrm{CO}_{2}$ was absorbed from the air by the solution in $A$, hence the increase in $A$ shows that bicarbonate moved from $C$ through $B$ into $A$ (we know from the partition coefficient that the amount of bicarbonate moving into $A$ was more than $B$ contained at the start). It is therefore evident that a continuation of this process would equalize the concentration of bicarbonate in $A$ and $C$ and hence

\footnotetext{
${ }^{30}$ The sap consists of $\mathrm{KCl}$ and $\mathrm{NaCl}$ with a trace of $\mathrm{CaCl}_{2}$ and $\mathrm{MgCl}_{2}$ : the organic matter is about 1.4 parts per thousand.

${ }^{31}$ For entrance of $\mathrm{CO}_{2}$ into Valonia see Brooks, M. M., Pub. Health Rep., U. S. P. H. S., 1923, 38, 1470; Osterhout, W. J. V., and Dorcas, M. J., J. Gen. Physiol., 1925-26, 9, 255; Jacques, A. G., and Osterhout, W. J. V., J. Gen. Physiol., 1929-30, 13, 695 .
} 
that the system does not move toward a Donnan equilibrium in which bicarbonate cannot escape from $C$.

This is confirmed by another experiment in which 1 liter of fresh guaiacol- $p$ cresol mixture (not shaken with $\mathrm{KOH}$ ) was placed in $B$. In $C$ was placed $100 \mathrm{cc}$. of $0.63 \mathrm{KHCO}_{3}$ and in $A 2$ liters of $0.05 \mathrm{M} \mathrm{KG}$. The system (Model I) was left to itself for 28 days (the stirring being continued but with no outside flow). At the end of this period $C$ contained $105 \mathrm{cc}$. the concentrations being $0.16 \mathrm{~m}$ potassium and $0.063 \mathrm{M}$ bicarbonate (hence $0.097 \mathrm{M} \mathrm{KG}$ ). $B$ contained $0.023 \mathrm{M}$ potassium (mostly $\mathrm{K} G$ ). A contained $0.06 \mathrm{M}$. potassium and $0.013 \mathrm{M}$ bicarbonate (hence $0.057 \mathrm{~K} G$ ). All of this bicarbonate $(25$ millimols) must have moved from $C$ through $B$ into $A$ since practically none was absorbed from the air.

Let us now consider the process of accumulation more in detail. In addition to the inward rate of diffusion of $\mathrm{K} G$, which we may call $R_{\mathrm{K} G}$, we must consider the outward rate of diffusion of $\mathrm{KHCO}_{3}$, which we may call $R_{\mathrm{KHCO}}$. It is evident that potassium will go on accumulating as long as $R_{\mathrm{KG}}$ is greater than $R_{\mathrm{KHCO}}$. This might happen even though acid were escaping from $C$ into $A$ provided the concentration of acid in $C$ did not fall so low that $R_{\mathrm{KG}}$ ceased to exceed $R_{\mathrm{KHCO}_{3}}{ }^{32}$ Evidently equilibrium cannot occur as long as acid is escaping, and it is evident that no equilibrium occurs in our experiments. As far as $\mathrm{K} G$ is concerned equilibrium is reached when $\left(\mathrm{K}_{i}\right)\left(G_{i}\right)$ is equal to $\left(K_{o}\right)\left(G_{o}\right)$, regardless of the nature of the membrane.

Accumulation while acid is escaping is illustrated by earlier experiments where, after placing $\mathrm{KOH}$ in $A$ and acid in $C$, the system was left to itself (with no renewal of solutions). We found that potassium entered freely and accumulated (page 673) but at the same time acid passed from $C$ into $A$, such acids as carbonic, formic, and citric coming out rapidly ( $\mathrm{HCl}$ came out more slowly and there was accumulation as described on page 673).

The relation of this to the Donnan principle need not be discussed at length. None of our results conflicts with this principle. If we call the acid inside $\mathrm{H} Z$ we may say that the more slowly $Z$-diffuses out the more nearly will the situation resemble that treated by Donnan. There is, however, this difference. If $Z$ be a non-penetrating ion the system will approach an equilibrium where the composition of $A$

${ }^{32}$ A rise in $\mathrm{pH}$ value in $C$ would hinder the transformation of $\mathrm{K} G$ to $\mathrm{KHCO}_{3}$ thereby lessening $R_{\mathrm{K}} G$. 
will not be identical with that of $B$. But if $Z^{-}$and the other ions penetrate even to a slight extent the system will move toward an equilibrium where $A$ and $C$ will be identical in composition (as in our experiments). When the system is prevented from reaching this equilibrium and a steady state is created by constant renewal of $Z^{-}$and movement of other substances (including water), there will be differences between $A$ and $C$ in the steady state not predictable by the Donnan equations (it may be remarked incidentally that these equations take no account of the movement of water or of increase in the total number of ions).

Let us now consider other models. MacDougal ${ }^{33}$ has described certain kinds. Our model, as previously mentioned, is a modification of that of Irwin. Models showing accumulation have been described by Netter ${ }^{34}$ and by Northrop..$^{35}$ The latter resemble ours more than do those of Netter. For example, in one of Northrop's experiments acetic acid passed through a collodion membrane and reacted with $\mathrm{CaCO}_{3}$, giving $\mathrm{CO}_{2}$ and calcium acetate. This may be compared with our experiment in which $\mathrm{KOH}$ passes in and reacts with $\mathrm{CO}_{2}$ to form water and $\mathrm{KHCO}_{3}$. In both cases a reactant was added as a separate phase (solid $\mathrm{CaCO}_{3}$, gaseous $\mathrm{CO}_{2}$ ) to avoid a large excess of neutralizing material in solution and in both cases the inside contained more reactant than the outside.

Straub $^{36}$ has recently described models in which an E.M.F. is employed to produce a steady state. In a different sort of experiment oxalic acid was allowed to diffuse out of a porous pot and react with marble ( $0.1 \mathrm{M} \mathrm{LiCl}$ being placed inside and outside) until a steady state was reached. These experiments seem to differ in several respects from ours and we prefer not to attempt any detailed comparison.

9. The model resembles Valonia in that very little calcium or magnesium enters the non-aqueous layer as compared with potassium and sodium.

${ }^{33}$ MacDougal, D. T., Proc. Am. Phil. Soc., 1928, 67, 33. MacDougal, D. T. and Moravek, V., Protoplasma, 1927, 2, 161.

${ }^{34}$ Netter, H., Arch. ges. Physiol., 1928, 220, 107.

${ }^{35}$ Northrop, J. H., J. Gen. Physiol., 1929-30, 13, 21.

${ }^{36}$ Straub, J., Chem. Weekbl., 1930, 27, 672. 
This is shown by the following experiment with Model I. A contained $0.1 \mathrm{M}$ $\mathrm{KCl}, 0.1 \mathrm{M} \mathrm{NaCl}, 0.1 \mathrm{M} \mathrm{CaCl}_{2}$, and $0.1 \mathrm{M} \mathrm{MgCl}_{2}$ (volume 2 liters). $B$ contained 1 liter of guaiacol- $p$-cresol mixture; $C$ contained $100 \mathrm{cc}$. distilled water. All three were stirred by glass stirrers. At the end of 154 hours (during which loss of evaporation from $A$ and $C$ was compensated by adding water) the following concentrations was found in $C: 0.06 \mathrm{M}$ potassium, $0.03 \mathrm{M}$ sodium, $0.0017 \mathrm{M} \mathrm{cal-}$ cium, and $0.0005 \mathrm{M}$ magnesium.

10. The model resembles Valonia in that chloride enters more readily than sulfate but the difference is much greater in the case of Valonia.

A model of the same dimensions as Model $\mathrm{I}$ in which $A$ was a mixture of $0.1 \mathrm{M}$ $\mathrm{KOH}$ and $0.1 \mathrm{M} \mathrm{NaOH}$ and $C$ was $100 \mathrm{cc}$. of a mixture of $0.4 \mathrm{M} \mathrm{H}_{2} \mathrm{SO}_{4}$ and $0.4 \mathrm{M}$ $\mathrm{HCl}$ was allowed to run for 8 days. At the end of this time the chloride and sulfate content of $A$ was determined and found to be $0.01 \mathrm{M}$ and $0.0036 \mathrm{M}$ respectively, hence chloride passed from $C$ through $B$ into $A$ about three times as rapidly as sulfate.

11. The use of a continuous non-aqueous layer to represent the protoplasmic surface seems to be necessary for reasons which have been dealt with elsewhere. ${ }^{37}$ Since our object is to illustrate the principles governing accumulation in Valonia rather than to discover the actual substances concerned, we are at liberty to choose any non-aqueous substance. Of course the fact that certain phenols seem suitable for our purpose does not imply that the protoplasmic surface is composed of these substances.

12. $\mathrm{KOH}$ penetrates more rapidly than $\mathrm{KCl}{ }^{3}$ This is shown by experiments in which $0.05 \mathrm{M} \mathrm{KCl}$ is placed in $A$ instead of $0.05 \mathrm{M} \mathrm{KOH}$. When this is done the penetration is extremely slow.

Let us now consider certain features of the mechanism of penetration. Since KOH combines at the outer surface of $B$ with an organic acid which we may call $\mathrm{HX}$, the reaction may be written

$$
\mathrm{KOH}+\mathrm{HX}=\mathrm{KX}+\mathrm{HOH} \text {. }
$$

At the inner surface of $B$ another reaction takes place,

$$
\mathrm{KX}+\mathrm{H}_{2} \mathrm{CO}_{3}=\mathrm{KHCO}_{3}+\mathrm{HX} .
$$

The molecule of $\mathrm{H} X$ thus formed may be presumed to return to the outer surface of $B$, there to react with $\mathrm{KOH}$. The net result is that $A$

${ }^{37}$ Osterhout, W. J. V., Biol. Rev., 1931, 6, 402. 
loses a potassium ion and $C$ loses a hydrogen ion. This is thermodynamically equivalent to an exchange of $\mathrm{K}^{+}$for $\mathrm{H}^{+}$, but the mechanism involved may be very different from a simple passage of $\mathrm{K}^{+}$and $\mathrm{H}^{+}$in opposite directions through the non-aqueous layer. For according to current conceptions potassium must exist in the non-aqueous layer chiefly in undissociated form, ${ }^{38}$ as molecules or as non-conducting ion pairs which for our present purpose amounts to the same thing. For convenience we shall not try to distinguish between them but we shall speak of such non-conducting ion pairs as molecules.

In order to attribute the major importance to ionic exchange it would be necessary to assume that the mobilities of $\mathrm{K}^{+}$and $\mathrm{H}^{+}$, for example, are very high as compared with those of molecules of $\mathrm{K}$-guaiacolate and of guaiacol. As the results of Walden ${ }^{39}$ and others indicate that not over 10 per cent of dissociation is to be expected in substances with so low a dielectric constant, ${ }^{40}$ the velocity of the slower ion of the exchanging pair would have to be at least 100 times as great as that of the corresponding molecule in order to make the total ionic transport in one direction ten times as great as the molecular.

One important feature of the hypothesis is not represented in the model: the fact that in Valonia $\mathrm{KCl}$ rather than $\mathrm{KHCO}_{3}$ accumulates has been discussed in previous papers where it is suggested that $\mathrm{HCO}_{3}^{-}$(passing through the non-aqueous layer as such or as undissociated $\mathrm{CO}_{2}$ or $\mathrm{H}_{2} \mathrm{CO}_{3}$ ) is exchanged for $\mathrm{Cl}^{-}$from the sea water (which may pass through the non-aqueous layer as such or as undissociated $\mathrm{HCl}$ ). Our experiments in this connection are not yet complete.

\section{SUMMARY}

Inasmuch as attempts to explain accumulation by the Donnan principle have failed in the case of Valonia, a hypothesis of the steady state has been formulated to explain what occurs. In order to see

${ }^{38}$ This would be true of all salts of potassium, whether organic or inorganic.

${ }^{39}$ Walden, P., Elektrochemie nichtwässriger Lösungen, Johann Ambrosius Barth, Leipsic, 1924.

${ }^{40}$ The dielectric constant of $p$-cresol at $24^{\circ} \mathrm{C}$. is 5.6 and of supercooled guaiacol is 11.7 (International critical tables, New York, McGraw-Hill Book Co., Inc., $1929,6,92)$. 
whether this hypothesis is in harmony with physico-chemical laws attempts have been made to imitate its chief features by means of a model.

The model consists of a non-aqueous layer (representing the protoplasmic surface) placed between an alkaline aqueous phase (representing the external solution) and a more acid aqueous phase (representing the cell sap).

The model reproduces most of the features of the hypothesis. Attention may be called to the following points.

1. The semipermeable surface is a continuous non-aqueous phase.

2. Potassium penetrates by combining with an acid $H X$ in the nonaqueous layer to form $\mathrm{KX}$ which in turn reacts with an acid $\mathrm{H} A$ in the sap to form $\mathrm{K} A$. Since $\mathrm{K} X$ is little dissociated in the non-aqueous layer potassium appears to pass through it chiefly in molecular form.

3. The internal composition depends on permeability, e.g., sodium penetrates less rapidly than potassium and in consequence potassium predominates over sodium in the "artificial sap." The order of penetration in the model is the same as in Valonia, i.e., $\mathrm{K}>\mathrm{Na}>\mathrm{Ca}>$ $\mathrm{Mg}$, and $\mathrm{Cl}>\mathrm{SO}_{4}$, but the quantitative resemblance is not close, e.g., the difference between potassium and sodium, and chloride and sulfate is much less in the model.

4. The formation of $\mathrm{KA}$ and $\mathrm{Na} A$ in the sap raises its osmotic pressure and water enters.

5. The concentration of potassium and sodium and the osmotic pressure become much greater inside than outside. For example, potassium may become 200 times as concentrated inside as outside.

6. No equilibrium occurs but a steady state is reached in which water and salt enter at the same rate so that the composition of the sap remains constant as its volume increases.

7. Since no equilibrium occurs there is a difference of thermodynamic potential between inside and outside. At the start the thermodynamic potential of $\mathrm{KOH}$ is much greater outside than inside. This difference gradually diminishes and in the steady state has about the same value as in Valonia. The difference in $\mathrm{pH}$ value between the internal and external solutions is also similar in both cases (about 2 pH units). 
8. Accumulation does not depend on the presence of molecules or ions inside which are unable to pass out.

One important feature of the hypothesis is not seen in the model: this is the exchange of $\mathrm{HCO}_{3}$ for $\mathrm{Cl}^{-}$. Experiments on this point are in progress. 